\title{
Differential vocational rehabilitation service patterns and outcomes for transition-age youth with specific learning disabilities: Implications in the COVID-19 era
}

\author{
Cahit Kaya ${ }^{\mathrm{a}, *}$, Sharon Hsu ${ }^{\mathrm{b}}$, Phillip D. Rumrill ${ }^{\mathrm{c}}$, Cheryl Hanley-Maxwell ${ }^{\mathrm{d}}$ and Fong Chan ${ }^{\mathrm{e}}$ \\ ${ }^{a}$ Giresun University, Giresun, Turkey \\ ${ }^{\mathrm{b}}$ Independent Researcher \\ ${ }^{\mathrm{c}}$ University of Kentucky, Lexington, KY, USA \\ ${ }^{\mathrm{d}}$ University of Illinois at Urbana-Champaign, Champaign, IL, USA \\ ${ }^{\mathrm{e}}$ University of Wisconsin-Madison, Madison, WI, USA
}

Received 18 January 2020

Accepted 10 August 2020

\begin{abstract}
.
BACKGROUND: It is essential to ensure that youth with specific learning disabilities (SLD) receive an appropriate type and amount of vocational rehabilitation (VR) services to facilitate their entrance to employment and career development.

METHODS: In this study, the chi-squared automatic interaction detector (CHAID) analysis and multivariate logistic regression analysis were used to investigate the relationship among demographic variables, VR services, and employment outcomes for transition-age youth with SLD.

RESULTS: Results indicated that age, gender, race, educational level, and cash benefits from the Social Security Administration were significant predictors of employment outcomes for transition-age youth with SLD. After controlling for the effects of demographic variables, job and training related services had significant relationships with employment outcomes. Most notably, job placement, occupational/vocational training, and on-the-job support services had the strongest relationships with competitive employment outcomes.
\end{abstract}

CONCLUSION: These findings support the effectiveness of job-related services and supported employment for transitionage youth with SLD. Implications for future research and practice in the wake of the COVID-19 pandemic are discussed.

Keywords: Rehabilitation, specific learning disability, transition-age youth, competitive employment

\section{Introduction}

Specific learning disability (SLD) has been the largest special education category for decades, constituting a range from $34 \%$ to $45.4 \%$ of Americans ages 3 to 21 who receive special education services (National Center for Education Statistics, 2013, 2019). U.S. public schools have adopted the Individu-

*Address for correspondence: Cahit Kaya, Department of Educational Sciences, Giresun University, Giresun, Turkey. Tel.: +90 5056931665; E-mail: rehber.cahit@gmail.com. als with Disabilities Education Act (IDEA) definition of SLD since the mid-1970s, which holds that:

SLD means a disorder in one or more of the basic psychological processes involved in understanding or in using language, spoken or written, that may manifest itself in the imperfect ability to listen, think, speak, read, write, spell, or to do mathematical calculations, including conditions such as perceptual disabilities, brain injury, minimal brain dysfunction, dyslexia, and developmental 
aphasia. Specific learning disability does not include learning problems that are primarily the result of visual, hearing, or motor disabilities, of intellectual disability, of emotional disturbance, or of environmental, cultural, or economic disadvantage [IDEA, 2004, Sec. 300.8 (c) (10)].

The term "specific" was added to learning disability to accentuate that individuals can have difficulties only in specific areas of learning, such as reading, writing, spelling, oral expression, calculating, information processing, and organization. At the same time, they perform at average or above-average levels in other areas of learning.

According to the National Center for Learning Disabilities (NCLD, 2014), approximately two-thirds (66\%) of students with SLD are boys, whereas the overall enrollment of boys in public schools is $51 \%$. This overrepresentation of boys with SLD occurs across all racial and ethnic groups. Most students with SLD are found in households living in poverty. Black and Hispanic students are overrepresented in SLD diagnoses, whereas Caucasian and Asian students are underrepresented. Students with SLD have the highest dropout rates among all students with disabilities. Approximately $68 \%$ of individuals with SLD receive a high school diploma, and $54 \%$ have a goal of attending two- or four-year college. One in two students with SLD experiences a disciplinary removal, such as suspension or expulsion. One in two young adults with SLD reported having some type of involvement with the criminal justice system within eight years of leaving high school. Furthermore, one in three have been arrested.

Working is a significant indicator of adult autonomy and success in the U.S. It is how people contribute to society and increase their economic selfsufficiency (Fernandes \& Gabe, 2009). Youth with SLD demonstrate different types and levels of difficulties and strengths in comparison to their nondisabled peers (Cummings et al., 2000; Hitchings \& Retish, 2000). Approximately 57 to $69 \%$ of youths with SLD have the goal to attain competitive employment in their individualized education programs (IEP), and $43 \%$ would like to attend a postsecondary vocational training program (NLTS-2, 2003). However, many youths with SLD lack a clear understanding of their disabilities and the potential impact of their disabilities on their ability to perform a job (Hitchings \& Retish, 2000). Consequently, many of them make uninformed career decisions that may lead to unemployment or underemployment.
SLD is a lifelong disability and often impacts individuals in the workplace. In one study, only approximately $46 \%$ of youth with SLD held regular paid employment within two years of leaving high school (Cameto et al., 2003). Additionally, youth with SLD experience a higher rate of unemployment and underemployment, fewer work hours, lower wages, and lower annual incomes as adults compared with their counterparts without disabilities (Kaye, 2005; Reder, 1995). The National Center for Learning Disabilities (NCLD, 2014) identified the following five reasons why youth with SLD experience challenges at work: inefficiency due to the slow pace of work, lack of accuracy associated with a high error rate on reading tasks and/or written correspondence, difficulty in the sequencing of tasks because of problems following instructions or completing projects with multiple steps, time management and difficulty with planning, and poor social skills.

In addition to these predominant challenges, many people with SLD struggle with soft skills, self-determination (Price et al., 2003) and difficulties in comprehension, sensory processing, communication, and social functioning. As the results of these challenges, they may face numerous obstacles to securing and maintaining employment (Rubin et al., 2016). Although youth with SLD value and strive for employment success, they often face challenges and require interventions and support services to prepare them to work and retain employment (Strauser, 2014).

The transition process is a coordinated set of activities designed to facilitate the movement of youth with disabilities from high school to postsecondary life, including independent living, postsecondary education, community participation, and employment (U.S. Department of Education, 2007). Daviso and colleagues (2011) reported that, among the transition services provided to youth with SLD, supported employment, career and technical education, job shadowing, and extracurricular activities produced the most favorable outcomes. Furthermore, high school employment experiences, parental expectations for post-school employment, arrest record, and school type were predictors of future employment outcomes (Fullarton \& Duquette, 2013; Wehman et al., 2015). McGee (2011) found that youth with SLD acquired less social capital than their peers through high school and demonstrated the need for more support services for this population to improve their postsecondary educational and employment outcomes.

VR support services have documented positive impacts on the employment outcomes of youth with 
SLD. For instance, Dunham and colleagues (1999) showed that $58.9 \%$ of individuals with SLD who received VR services obtained employment. Additionally, $56 \%$ of people with SLD and co-occurring intellectual disabilities obtained competitive employment after receiving VR services (Dunham et al., 2000). More recently, Gonzalez et al. (2011) revealed that $62.4 \%$ of youth with SLD obtained competitive employment after receiving VR services. Most of the VR services for individuals with SLD were on-the-job training, job coaching, and counseling services (Dunham et al., 2000). Among VR services, job placement, college training and occupational training were significant predictors of positive employment outcomes for transition-age youth with SLD (Swanson, 2017). However, both postsecondary education and VR counseling services were negatively associated with competitive employment for youth with SLD (Dunham et al., 1999).

Although existing studies have documented the positive impact of VR services on the employment outcomes of youth with SLD, more research is needed to 1) investigate the intersectionality of demographic variables and employment outcomes; and 2) examine the extent to which personal factors and VR service provision patterns conjointly predict employment outcomes among young adults with SLD. The purpose of this study was to examine the relationships among individual characteristics, VR services, and employment outcomes of transition-age youth with SLD, using the Rehabilitation Services Administration Case Service Report (RSA-911) Fiscal Year 2013 dataset. The fiscal year 2013 dataset was used because it was at that time when the US economy had begun to recover from the Great Recession (2008-2010). The researchers determined that FY 2013 data represented a more typical economy than was evident during either the Great Recession or the extremely robust growth years immediately preceding the Coronavirus pandemic. It remains to be seen what impact the COVID-19 crisis will have on the global economy and on the employment of people with disabilities in the years to come.

\section{Method}

\subsection{Data source}

The Rehabilitation Services Administration (RSA) annually collects demographic and VR service-related data concerning individuals who have received services from state VR agencies. These data are stored in RSA's Case Service Report, RSA-911 data base. To obtain RSA-911 data, rehabilitation researchers need to provide a description of their research projects and rationale for using the RSA911 data to RSA. RSA then reviews the request and shares the data if approved. This approval process was followed in this study.

\subsection{Participants}

The study sample included 9,114 young adult VR consumers with SLD. Inclusion criteria were: 1) age between 19 and 25 at the time of application; 2) unemployed at the time of application; and 3) VR case closed during Fiscal Year 2013. In the present study, most participants were between 19 and 22 years old (82.2\%), male (60.5\%), non-Caucasian (53\%), with at least a high school diploma or higher levels of education (50.4\%), and not recipients of Supplemental Security Income (SSI) or Social Security Disability Insurance (SSDI; 86.7\%). Table 1 provides a detailed description of the demographic characteristics of the sample.

\subsection{Measures}

\subsubsection{Independent variables}

This study had two sets of independent variables: demographic variables and VR services. Demographic variables included gender, race (Caucasian,

Table 1

Demographic characteristics of transition-age youth with specific learning disabilities

\begin{tabular}{lcc}
\hline Demographic characteristics & $N$ & $\%$ \\
\hline Age & & \\
19-22 & 7,495 & 82.2 \\
$23-25$ & 1,619 & 17.8 \\
Gender & & \\
$\quad$ Male & 5,511 & 60.5 \\
Female & 3,603 & 39.5 \\
Race & & \\
Caucasian & 4,363 & 47.9 \\
African-American & 2,736 & 30.0 \\
American Indian or Alaska Native & 143 & 1.6 \\
Asian, Native Hawaiian & 160 & 1.8 \\
$\quad$ or Pacific Islander & & \\
$\quad$ Hispanic or Latino & 1,712 & 18.8 \\
Education level & & \\
$\quad$ Special education & 1,549 & 17.0 \\
Less than high school & 2,975 & 32.6 \\
High school & 3,561 & 39.1 \\
Associate degree & 989 & 10.9 \\
Bachelor degree or higher & 40 & 0.4 \\
SSI/SSDI recipient & & \\
$\quad$ Yes & 1,210 & 13.3 \\
No & 7,904 & 86.7 \\
\hline
\end{tabular}


Table 2

Description of vocational rehabilitation services

\begin{tabular}{l} 
Types of services \\
\hline Assessment \\
Diagnosis and treatment \\
of impairments
\end{tabular}

Vocational rehabilitation counseling and guidance

\section{College or university training}

Occupational/vocational training

On-the-job training

Basic academic remedial or literacy training $J$ ob readiness training

Disability-related, augmentative skills training Miscellaneous training

Job search assistance

Job placement assistance On-the-job supports

Transportation services

Maintenance services

Rehabilitation technology

Reader services

Interpreter services
Descriptions of services

Services provided and activities performed to determine an individual's eligibility for vocational rehabilitation services, to assign an individual to a priority category of a state vocational rehabilitation agency that operates under an order of selection, and/or to determine the nature and scope of vocational rehabilitation services to be included in the Individual Plan for Employment (IPE); included in this category are trial work experiences and extended evaluation. Surgery, prosthetics and orthotics, nursing services, dentistry, occupational therapy, physical therapy, speech therapy, and drugs and supplies; this category includes diagnosis and treatment of mental and emotional disorders.

Discrete therapeutic counseling and guidance services necessary for an individual to achieve an employment outcome, including personal adjustment counseling; counseling that addresses medical, family, or social issues; vocational counseling; and any other form of counseling and guidance necessary for an individual with a disability to achieve an employment outcome; this service is distinct from the general counseling and guidance relationship that exists between the counselor and the individual during the entire rehabilitation process.

Full-time or part-time academic training above the high school level that leads to a degree (associate, baccalaureate, graduate, or professional), a certificate, or other recognized educational credential; such training may be provided by a four-year college or university, community college, junior college, or technical college.

Occupational, vocational, or job skill training provided by a community college and/or a business, vocational/trade, or technical school to prepare students for gainful employment in a recognized occupation; this training does not lead to an academic degree or certification.

Training in specific job skills by a prospective employer; generally the individual is paid during this training and will remain in the same or a similar job upon successful completion; this category also includes apprenticeship training programs conducted or sponsored by an employer, a group of employers, or a joint apprenticeship committee representing both employers and a union. Literacy training or training provided to remediate basic academic skills needed to function on the job in the competitive labor market.

Training to prepare an individual for the world of work (e.g., appropriate work behaviors, methods for getting to work on time, appropriate dress and grooming, methods for increasing productivity). Service includes, but is not limited to, orientation and mobility, rehabilitation teaching, training in the use of low vision aids, Braille, speech reading, sign language, and cognitive training/retraining. Any training not recorded in one of the other categories listed, including GED or high school training leading to a diploma.

Job search activities that support and assist a consumer in searching for an appropriate job; may include help in preparing resumes, identifying appropriate job opportunities, and developing interview skills, and may include making contacts with companies on behalf of the consumer. A referral to a specific job resulting in an interview, whether or not the individual obtained the job. Support services provided to an individual who has been placed in employment in order to stabilize the placement and enhance job retention; such services include job coaching, follow-up and follow-along, and job retention services.

Travel and related expenses necessary to enable an applicant or eligible individual to participate in a vocational rehabilitation service; includes adequate training in the use of public transportation vehicles and systems.

Maintenance means monetary support provided for those expenses such as food, shelter and clothing that are in excess of the normal expenses of the individual, and that are necessitated by the individual's participation in an assessment for determining eligibility and vocational rehabilitation needs or while receiving services under an individualized plan for employment (IPE).

The systematic application of technologies, engineering methodologies, or scientific principles to meet the needs of, and address the barriers confronted by, individuals with disabilities in areas that include education, rehabilitation, employment, transportation, independent living, and recreation; includes rehabilitation engineering services, assistive technology devices, and assistive technology services.

Services for individuals who cannot read print because of blindness or other disability; includes reading aloud and transcribing printed information into Braille or sound recordings if requested by the individual; generally are offered to individuals who are blind or deaf-blind but may also be offered to individuals unable to read because of serious neurological disorders, specific learning disabilities, or other physical or mental impairments.

Sign language or oral interpretation services performed by specially trained persons for individuals who are deaf or hard of hearing, and tactile interpretation services for individuals who are deaf-blind; includes real-time captioning services; does not include language interpretation. 
Table 2

Continued

\begin{tabular}{ll}
\hline Types of services & Descriptions of services \\
\hline $\begin{array}{l}\text { Personal attendant } \\
\text { services }\end{array}$ & Those personal services that an attendant performs for an individual with a disability such \\
Technical assistance & as bathing, feeding, dressing, providing mobility and transportation, and so on. \\
services & Technical assistance and other consultation services provided to conduct market analyses, to \\
develop business plans, and to provide resources to individuals & in the pursuit of self-employment, telecommuting, and small business operation outcomes. \\
Information and & Services provided to individuals who need assistance from other agencies \\
referral services & (through cooperative agreements) not available through the vocational rehabilitation program. \\
Other services & All other vocational rehabilitation services that cannot be recorded elsewhere; included here are \\
& occupational licenses, tools and equipment, initial stocks and supplies, and medical care for acute \\
& conditions arising during rehabilitation and constituting a barrier to the achievement \\
& of an employment outcome.
\end{tabular}

African-American, American Indian or Alaska Native, Asian, Native Hawaiian or Pacific Islander, or Hispanic or Latino), education level (special education, less than high school education, high school graduate, associate's degree, bachelor's degree or higher), and receipt of disability cash benefits (SSI/ SSDI recipient or non-recipient). Although receipt of disability cash benefits was used as a proxy for disability severity, it should be noted that it may also reflect poverty status among participants. VR services included a variety of support services that can be provided to youth with SLD. Table 2 provides detailed descriptions of VR services for FY 2013. Readers should note that the state-Federal VR program added pre-employment transition services after the passage of the Workforce Innovation and Opportunity Act [WIOA] and amendments of the Rehabilitation Act in 2014.

\subsubsection{Outcome variable}

This study used competitive employment as the outcome variable. RSA defines competitive employment as: "full time or part-time employment in an integrated setting; self-employment; or a state-managed Business Enterprise Program (BEP) where the employee is paid at or above the minimum wage depending upon federal or state minimum wage, whichever is higher" (Rehabilitation Services Administration, 2005, p. 33). Participants who did not achieve competitive employment outcomes after receiving VR services were considered to have unsuccessful outcomes.

\subsection{Statistical analyses}

Descriptive statistical analyses were used to provide information about the demographic characteristics of the participants in this study. To answer research question \#1, the intersectionality between demographic variables and employment outcomes was investigated using Chi-squared Automatic Interaction Detector (CHAID) analysis. For research question \#2, we computed a multivariate logistic regression analysis to examine the relationships among demographic variables, VR services, and employment outcomes.

\section{Results}

\subsection{VR services and employment outcomes}

The results of descriptive analyses indicated that $56.1 \%$ of transition-age youth with SLD achieved competitive employment. It should be noted that, in $2013,17.6 \%$ of people with a disability were employed. In contrast, the employment-population ratio for those without a disability was $64.0 \%$ (U.S. Bureau of Labor Statistics, 2015). Receiving VR services significantly improve the odds of finding employment for youth with SLD. The average number of services provided to study participants was 4.00 $(S D=2.23)$. VR counseling and guidance $(57.2 \%)$, assessment (54.4\%), and job placement (43.5\%) were the three most frequently provided services. Frequencies of all VR services provided to participants in the present study are shown in Table 3.

On average, individuals with SLD spent 25.67 $(S D=19.83)$ months in VR services, and the median cost that was associated with those services was $\$ 2,026$. Transition-age youth with SLD who were competitively employed received a larger number of services $(M=4.45, S D=2.27)$ than did those who were not competitively employed $(M=3.43$, $S D=2.06 ; t(8919)=22.44, p<0.001)$. Transition-age youth with SLD who were competitively employed also stayed in the VR system for a shorter time 
Table 3

VR services provided for transition-age youth with SLD $(\mathrm{N}=15239)$

\begin{tabular}{lcc}
\hline Services provided $(n=15239)$ & $n$ & $\%$ \\
\hline Assessment & 4,957 & 54.4 \\
Diagnostics and treatment & 1,962 & 21.5 \\
Counseling and guidance & 5,217 & 57.2 \\
College or university training & 1,169 & 12.8 \\
Occupational or vocational training & 1,329 & 14.6 \\
On-the-job training & 330 & 3.6 \\
Remedial training & 151 & 1.7 \\
Job readiness training & 1,509 & 16.6 \\
Augmentative skills training & 59 & 0.6 \\
Miscellaneous training & 1,105 & 12.1 \\
Job search assistance & 2,936 & 31.9 \\
Job placement assistance & 3,962 & 43.5 \\
On-the-job support & 1,925 & 21.1 \\
Transportation services & 3,027 & 33.2 \\
Maintenance & 1,397 & 15.3 \\
Rehabilitation technology & 198 & 2.2 \\
Reader & 153 & 1.7 \\
Interpreter & 11 & 0.1 \\
Personal attendant & 34 & 0.4 \\
Technical assistance & 142 & 1.6 \\
Information and referral & 1,636 & 18.0 \\
Other services & 2,284 & 25.1 \\
Supported employment & 1,051 & 11.5 \\
\hline
\end{tabular}

$(M=23.63$ months, $S D=19.46)$ than did those who were not competitively employed ( $M=28.28$ months, $S D=21.22 ; t(8219)=10.76, p<0.001)$. The median cost associated with VR services was higher for the competitively employed group $(M d n=\$ 3,080)$ than it was for the unemployed group $(M d n=\$ 1,182)$.

\subsection{Relationships between demographic variables and employment outcomes}

The CHAID analysis results provided more information about the relationships between demographic variables and competitive employment for youth with SLD. The results indicated that age, gender, race, educational level and cash benefits were significant predictors of employment outcomes. The results of the decision tree in table format for transition-age youth with SLD are shown in Table 4.

Additionally, results indicated that cash benefits were the strongest predictor of competitive employment rates for transition-age youth with SLD. Specifically, $57.9 \%$ of those who did not receive cash benefits achieved competitive employment at case closure, whereas $44.0 \%$ of those who received cash benefits achieved competitive employment. Furthermore, among individuals who received cash benefits, $49.2 \%$ of Caucasians and $40.3 \%$ of non-Caucasians achieved competitive employment. Within the group of Caucasians who received cash benefits, $45.9 \%$ of 19-22 year old individuals and $57.3 \%$ of $23-25$ year old individuals gained competitive employment. For those who did not receive any cash benefits, $58.5 \%$ who completed special education, $51.9 \%$ who had less than a high school education, $60.6 \%$ who had a high school diploma, and $64.5 \%$ who had an associate's degree or higher achieved competitive employment.

Among transition-age youth with SLD who did not receive cash benefits and had less than a high school diploma, $54.5 \%$ of males and $47.4 \%$ of females achieved competitive employment. Among those who did not receive cash benefits and had high school diplomas, $62.4 \%$ of Caucasian and African American individuals and $53.5 \%$ of individuals other than Caucasian and African Americans achieved competitive employment. Among transition-age youth with SLD who did not receive cash benefits and had an associate's degree or higher, $68.8 \%$ of male individuals and $60.0 \%$ of female individuals achieved competitive employment. A graphical depiction of the decision-tree can be requested from the senior author of this article.

\subsection{Relationships among demographic variables, VR services, and employment outcomes}

In the first step of the multivariate logistic regression analysis, the one-on-one relationships between independent and dependent variables were investigated. Among all of the demographic and VR service variables, only interpreter and basic academic remedial training did not have a significant relationship with competitive employment at $p>0.05$, n.s. Therefore, all of the other independent variables were entered into a logistic regression analysis. Age, assessment, vocational rehabilitation counseling, job readiness, miscellaneous training, job search, transportation, rehabilitation technology, readers, information and referral, and supported employment services were not significantly associated with competitive employment in the presence of other variables at $p>0.05$, n.s. The insignificant variables were removed from the model. None of them changed the beta coefficients of significant variables by more than $20 \%$. The basic academic remedial training, which was not significant in the first step, was put back into the regression model. It did not turn out to be statistically significant. 
Table 4

Decision tree in table format for transition-age youth with SLD

\begin{tabular}{|c|c|c|c|c|c|c|}
\hline & \multicolumn{2}{|c|}{$\begin{array}{l}\text { Unsuccessful } \\
\text { outcome }\end{array}$} & \multicolumn{2}{|c|}{$\begin{array}{l}\text { Competitive } \\
\text { employment }\end{array}$} & \multirow[b]{2}{*}{$X^{2}$} & \multirow[b]{2}{*}{$p$} \\
\hline & $n$ & $\%$ & $n$ & $\%$ & & \\
\hline Transition-age youth with SLD & 4004 & $43.9 \%$ & 5110 & $56.1 \%$ & & \\
\hline $\begin{array}{l}\text { Transition-age youth with SLD } \\
\text { who did not receive cash benefits }\end{array}$ & 3326 & $42.1 \%$ & 4578 & $57.9 \%$ & 82.941 & 0.000 \\
\hline $\begin{array}{l}\text { Transition-age youth with SLD } \\
\text { who received cash benefits }\end{array}$ & 678 & $56.0 \%$ & 532 & $44.0 \%$ & 82.941 & 0.000 \\
\hline $\begin{array}{l}\text { Transition-age youth with SLD who did } \\
\text { not receive cash benefits and had special education }\end{array}$ & 519 & $41.2 \%$ & 742 & $58.8 \%$ & 65.084 & 0.000 \\
\hline $\begin{array}{l}\text { Transition-age youth with SLD who did not receive } \\
\text { cash benefits and had less than high school degree }\end{array}$ & 1245 & $48.1 \%$ & 1342 & $51.9 \%$ & 65.084 & 0.000 \\
\hline $\begin{array}{l}\text { Transition-age youth with SLD who did not receive } \\
\text { cash benefits and had high school degree }\end{array}$ & 1226 & $39.4 \%$ & 1883 & $60.6 \%$ & 65.084 & 0.000 \\
\hline $\begin{array}{l}\text { Transition-age youth with SLD who did not receive } \\
\text { cash benefits and had associated degree or higher }\end{array}$ & 336 & $35.5 \%$ & 611 & $64.5 \%$ & 65.084 & 0.000 \\
\hline $\begin{array}{l}\text { Transition-age youth with SLD who received } \\
\text { cash benefits and were Caucasian }\end{array}$ & 253 & $50.8 \%$ & 245 & $49.2 \%$ & 9.396 & 0.009 \\
\hline $\begin{array}{l}\text { Transition-age youth with SLD who received cash } \\
\text { benefits and were other than Caucasian }\end{array}$ & 425 & $59.7 \%$ & 287 & $40.3 \%$ & 9.396 & 0.009 \\
\hline $\begin{array}{l}\text { Transition-age youth with SLD who did not receive } \\
\text { cash benefits, had special education and were 19-22 years old }\end{array}$ & 477 & $43.3 \%$ & 624 & $56.7 \%$ & 16.816 & 0.000 \\
\hline $\begin{array}{l}\text { Transition-age youth with SLD who did not receive cash benefits, } \\
\text { had special education and were } 23-25 \text { years old }\end{array}$ & 42 & $26.3 \%$ & 118 & $73.8 \%$ & 16.816 & 0.000 \\
\hline $\begin{array}{l}\text { Transition-age youth with SLD who did not receive cash benefits, } \\
\text { had less high school degree and were male }\end{array}$ & 745 & $45.5 \%$ & 891 & $54.5 \%$ & 11.934 & 0.001 \\
\hline $\begin{array}{l}\text { Transition-age youth with SLD who did not receive cash benefits, } \\
\text { had less high school degree and were female }\end{array}$ & 500 & $52.6 \%$ & 451 & $47.4 \%$ & 11.934 & 0.001 \\
\hline $\begin{array}{l}\text { Transition-age youth with SLD who did not receive cash benefits, } \\
\text { had high school degree and were Caucasian or African American }\end{array}$ & 930 & $37.6 \%$ & 1543 & $62.4 \%$ & 16.909 & 0.000 \\
\hline $\begin{array}{l}\text { Transition-age youth with SLD who did not receive cash benefits, } \\
\text { had high school degree and were Asian, Native Hawaiian } \\
\text { or Other Pacific Islander American Indian or Alaska } \\
\text { Native and Hispanic and Latinos }\end{array}$ & 296 & $46.5 \%$ & 340 & $53.5 \%$ & 16.909 & 0.000 \\
\hline $\begin{array}{l}\text { Transition-age youth with SLD who did not receive cash benefits } \\
\text { and had associated degree or higher and were male }\end{array}$ & 153 & $31.2 \%$ & 337 & $68.8 \%$ & 8.034 & 0.005 \\
\hline $\begin{array}{l}\text { Transition-age youth with SLD who did not receive cash benefits, } \\
\text { had associated degree or higher and were female }\end{array}$ & 183 & $40.0 \%$ & 274 & $60.0 \%$ & 8.034 & 0.005 \\
\hline $\begin{array}{l}\text { Transition-age youth with SLD who received cash benefits, } \\
\text { were Caucasian and 19-22 years old }\end{array}$ & 192 & $54.1 \%$ & 163 & $45.9 \%$ & 5.326 & 0.021 \\
\hline $\begin{array}{l}\text { Transition-age youth with SLD who received cash benefits, } \\
\text { were Caucasian and } 23-25 \text { years old }\end{array}$ & 61 & $42.7 \%$ & 82 & $57.3 \%$ & 5.326 & 0.021 \\
\hline
\end{tabular}

As for the final model, the omnibus test showed that the predictor variables were significantly related with competitive employment, $\chi^{2}(19, N=9,114)=$ $1,446.73, p<0.001$. The Nagelkerke $R^{2}$ of 0.19 indicated that predictors had a moderate effect on the outcome variable. The Hosmer and Lemeshow test pointed out that there is a lack of fit between the model and the data, $\chi 2(8, N=9,114=37.98, p<$ 0.01 (Kleinbaum \& Klien, 2010). However, in data with a large sample size, small differences may cause a misfit between the model and the data. The model accurately classified $73.9 \%$ of individuals who achieved competitive employment and $58.9 \%$ of individuals who had unsuccessful outcomes. The multivariate logistic regression results are presented in Table 5 .

As can be observed in Table 5, females $(O R=0.74$; 95\% CI 0.68-0.81) were less likely to achieve competitive employment than male consumers. Overall, African-Americans $(O R=0.78 ; 95 \%$ CI $0.70-0.87)$, American Indians-Alaskan Natives $(O R=0.54 ; 95 \%$ CI 0.37-0.79), and Hispanics or Latinos $(O R=0.83$; 95\% CI 0.74-0.94) were less likely to achieve competitive employment than Caucasians. However, there were no significant differences in the odds ratios of competitive employment rates between Caucasian and Asian, Native Hawaiian, or Other Pacific Islander participants. Participants who completed a special 
Table 5

The relationship between significant predictor variables and competitive employment for transition-age youth with SLD

\begin{tabular}{|c|c|c|c|c|c|c|}
\hline \multirow{2}{*}{$\begin{array}{l}\text { Predictors } \\
\text { Gender (Woman is the focal group) }\end{array}$} & \multirow{2}{*}{$\frac{\mathrm{B}}{-0.293}$} & \multirow{2}{*}{$\begin{array}{c}\text { SE B } \\
0.047\end{array}$} & \multirow{2}{*}{$\begin{array}{c}\text { Sig. } \\
0.000\end{array}$} & \multirow{2}{*}{$\begin{array}{c}\text { Odds ratio } \\
0.746\end{array}$} & \multicolumn{2}{|c|}{$95 \% \mathrm{CI}$} \\
\hline & & & & & 0.681 & 0.818 \\
\hline \multicolumn{7}{|l|}{ Race } \\
\hline Caucasian & & & 0.000 & & & \\
\hline African-American & -0.243 & 0.054 & 0.000 & 0.784 & 0.705 & 0.872 \\
\hline $\begin{array}{l}\text { American Indian } \\
\text { or Alaska Native }\end{array}$ & -0.604 & 0.189 & 0.001 & 0.546 & 0.377 & 0.791 \\
\hline Asian or Pacific Islander & 0.041 & 0.175 & 0.816 & 1.042 & 0.739 & 1.468 \\
\hline Hispanic or Latino & -0.176 & 0.062 & 0.005 & 0.839 & 0.742 & 0.948 \\
\hline Education level (Bachelor degree or higher) & & & 0.000 & & & \\
\hline Special education & -1.548 & 0.498 & 0.002 & 0.213 & 0.080 & 0.564 \\
\hline Less than high school & -1.818 & 0.496 & 0.000 & 0.162 & 0.061 & 0.430 \\
\hline High school graduate & -1.491 & 0.496 & 0.003 & 0.225 & 0.085 & 0.595 \\
\hline Associate degree & -1.261 & 0.500 & 0.012 & 0.283 & 0.106 & 0.755 \\
\hline Cash benefits & -0.695 & 0.069 & 0.000 & 0.499 & 0.436 & 0.572 \\
\hline \multicolumn{7}{|l|}{$\begin{array}{l}V R \text { services (Yes is the focal group; } \\
\text { No is the reference group) }\end{array}$} \\
\hline Diagnosis and treatment & -0.251 & 0.057 & 0.000 & 0.778 & 0.696 & 0.869 \\
\hline College or university training & 0.320 & 0.071 & 0.000 & 1.377 & 1.197 & 1.583 \\
\hline Occupational/vocational training & 0.625 & 0.067 & 0.000 & 1.869 & 1.637 & 2.133 \\
\hline On-the-job training & 0.429 & 0.139 & 0.002 & 1.536 & 1.169 & 2.019 \\
\hline Job placement assistance & 1.125 & 0.049 & 0.000 & 3.079 & 2.797 & 3.390 \\
\hline On-the-job supports & 0.912 & 0.063 & 0.000 & 2.488 & 2.200 & 2.814 \\
\hline Maintenance services & 0.386 & 0.068 & 0.000 & 1.472 & 1.289 & 1.680 \\
\hline Technical assistance services & 1.099 & 0.244 & 0.000 & 3.002 & 1.862 & 4.840 \\
\hline Other services & 0.280 & 0.055 & 0.000 & 1.323 & 1.187 & 1.473 \\
\hline
\end{tabular}

Note. Final model $=\chi^{2}(19, N=9114)=1446.73 p<0.001 ;$ Nagelkerke $R^{2}=0.19 ;$ Hosmer and Lemeshow $=\chi^{2}(8, N=9114)=37.98, p<0.01$.

education certificate $(O R=0.21 ; 95 \%$ CI $0.80-0.56)$, less than a high school education $(O R=0.16 ; 95 \%$ CI 0.06-0.43), or a high school diploma $(O R=0.22$; 95\% CI 0.06-0.43) were less likely to achieve competitive employment than those with a bachelor's degree or higher. However, there were no significant differences in odds ratios of competitive employment rates between transition-age youth with SLD who had an associate's degree and a bachelor's degree or higher. Transition-age youth with SLD who received cash benefits $(O R=0.49$; 95\% CI $0.43-0.57)$ were less likely to achieve competitive employment than those who did not receive cash benefits.

The odds of individuals receiving job placement services were three times $(O R=3.07$; 95\% CI: 2.79 3.39) more likely to obtain competitive employment than those who did not receive job placement services. Additionally, individuals receiving technical assistance services were three times $(O R=3.00 ; 95 \%$ CI: 1.86-4.84) more likely to obtain competitive employment than those who did not receive technical assistance services.

In terms of on-the-job support services, individuals receiving those services were two and a half times $(O R=2.48 ; 95 \%$ CI: $2.20-2.81)$ more likely to obtain competitive employment than those who did not receive on-the-job support services. The odds of individuals receiving on-the-job training services to obtain competitive employment were 1.53 times $(O R=1.53 ; 95 \%$ CI: $1.16-2.01)$ greater than the odds of those who did not receive on-the-job training services.

For individuals receiving maintenance services or college/university training services, the odds were approximately one and a half times $(O R=1.47 ; 95 \%$ CI: $1.28-1.68)$ and 1.37 times $(O R=1.37$; $95 \% \mathrm{CI}$ : 1.19-1.58) greater than the odds of those who did not receive maintenance services or college/university training services, respectively. Individuals who received diagnosis and treatment services had a $23 \%$ reduction in the odds of obtaining competitive employment $(O R=0.77 ; 95 \%$ CI: $0.69-0.86)$ in comparison to individuals who did not receive diagnosis and treatment services. Finally, individuals receiving occupational/vocational training were approximately twice as likely to obtain competitive employment $(O R=1.86 ; 95 \%$ CI: $1.63-2.13)$ when compared to those who did not receive occupational/ vocational training services, and individuals receiving other services were approximately one and a half 
times more likely to obtain employment $(O R=1.32$; 95\% CI: 1.18-1.47) than those who did not receive other services.

\section{Discussion}

Overall, these findings indicated that, among the demographic variables, cash benefits were the most important factor that differentiated competitively employed individuals from those who had unsuccessful outcomes. This result is in line with previous research indicating that cash benefits had a significant correlation with employment outcomes for people with SLD (Gonzales et al., 2009; Martin, 2010; Mambaleo et al., 2016). As transition-age youth with SLD who received cash benefits may have more severe disabilities, it stands to reason that they would have poorer employment outcomes (Strauser, 2014). It is also possible that receiving cash benefits might be a strong disincentive for obtaining competitive employment for transition-age youth with SLD (Wehman et al., 2015). Researchers have indicated that receiving cash benefits might cause underutilization of VR services and lack of motivation, which may negatively impact employment outcomes for transition-age youth with SLD (Gonzales et al., 2011). In addition to that, families with low incomes might encourage transition-age youth with SLD to remain on the public support system (Luecking \& Wittenburg, 2009) to ensure a regular source of income and other benefits. In the wake of the COVID19 pandemic, disability cash benefits recipients with SLD and other disabilities for that matter may be even more disinclined to seek, secure, and maintain competitive employment given the limited availability of jobs in the economy, the difficulty in arranging homebased employment through the use of technology, and the risk of contracting the Coronavirus in the event that available jobs require in person attendance.

Further, the present results suggested that being male, Caucasian, and having a higher level of education were positively associated with competitive employment. This finding is consistent with previous literature regarding people with SLD (Dunham et al. 2000; Gonzales et al., 2009; Ji et al., 2015). Researchers repeatedly find that people who come from culturally diverse or otherwise underprivileged backgrounds often feel less empowered and have cultural mistrust (Smart, 2020). Therefore, they may not be able to utilize resources effectively or fit within the employment service system (Ji et al., 2015). Male transition-age youth with LD might have a higher level of competitive employment due to the influence of traditional male roles and related expectations. This may, in turn, result in them being more ready for employment than their female counterparts (Powers et al., 2008).

The results also indicated that having an associate's degree or higher was significantly and positively related to employment outcomes. As more education and training make transition-age youth with SLD more competitive for possible job options, it follows that those who have more education would have more successful employment outcomes. Interestingly, there were no significant differences between an associate's degree and a bachelor's or higher degree in this study in terms of employment outcomes. This result may imply that transition-age youth who receive an associate's degree may be at a critical point in terms of functioning level, and those who pass this critical stage are equally capable of competitive employment regardless of whether they pursue education beyond that level. Certainly, these findings underscore the importance of encouraging young VR consumers with SLD who have the ability to pursue postsecondary education to do so as part of their VR programs. In the wake of the COVID19 pandemic, planning for postsecondary education must take into account the individual's information and communication technology skills, his or her ability to participate in online coursework, and the social distancing requirements that are in place if he or she elects to pursue in-person training.

Results also indicated that, after controlling for the effects of demographic variables (i.e. age, gender, race, education level, receipt of cash benefits), job and training related services had a significant relationship with employment outcomes. Most notably, job placement, occupational/vocational training, and on-the-job support services had the most robust associations with competitive employment for transition-age youth with SLD. The finding is consistent with other research findings that transition-age youth with SLD need intensive vocational and career preparatory services, all geared toward their individual needs (Ji et al., 2015). Transition-age youth with SLD might need more occupational, vocational, and job skills training from college or universities (Hendricks, 2010) to achieve better employment outcomes. It is also true that young people with SLD do not necessarily have physical or sensory disabilities that would limit their vocational choices, so providing job-related training for these individuals can be 
achieved within a wide range of occupational and career possibilities.

Our findings also indicated that transition-age youth with SLD who received a greater number of services, whose cases were implemented at higher levels of expenditure, and who spent less time in the VR program had higher employment success rates than other individuals receiving services. Clearly, this suggests a benefit inherent in service intensity, whereby individuals are actively engaged in numerous services over a limited period of time. This intensity of services may provide the needed support to keep individuals engaged and motivated thereby increasing the probability of successful outcomes (Winn \& Hay, 2009).

\subsection{Implications}

The significant impact of job placement and on-the-job support services vis a vis competitive employment outcomes in this study is important. This finding supports the effectiveness of job-related services and supported employment for transition-age youth with SLD and other disabilities. Rehabilitation professionals working with transition-age youth may conduct various ability and interest assessments, locate jobs that are available in their communities, and then match students with those jobs (Hendricks, 2010). This practice is in line with best transition practices (Kohler \& Field, 2003), such as involving employers in the transition process and collaboration between community organizations and transition programs to provide effective services (Blalock, 1996; Sabbatino \& Macrine, 2007; Oertle \& Trach, 2007). Transition-age youth with disabilities such as SLD, autism, and intellectual disabilities may not have sufficient skills to independently contact employers and set up job interviews without assistance, and these individuals may need extensive follow-along services once they are employed.

Of course, the recent COVID-19 outbreak has changed the manner, type, and delivery of transition and vocational services to young people with SLD and other disabilities. Additional research is needed to determine the effectiveness of virtually provided direct services across the continuum of supports that are available in the VR system for a variety of disability populations.

In this study, males, Caucasian consumers, and those with higher levels of education at the time of enrollment in VR services had higher success rates than did other consumers. Postsecondary edu- cation may provide more learning opportunities and job-related life experiences that result in higher competitive employment. However, privilege bias persists in virtually all service delivery systems, including VR, so counselors must be diligent in their efforts to ensure that women, people of color, people living in poverty, and those with lower levels of education at the time of enrollment in VR services have access to the same effective services to meet their needs that are provided to individuals whose demographic characteristics result in an advantaged status in our society (Rubin et al., 2016).

The demonstrated benefit of service intensity in this study has important implications. Employment opportunities are enhanced when individuals receive a larger number of services (and hence at a higher cost) over a shorter period of time. This may not be possible for all young adults with SLD, some of whom must progress through their VR programs at slower paces than others. However, keeping individuals motivated to pursue their vocational goals is an important element of individualized planning and case management (Dutta et al., 2008). Therefore, when VR services are provided in a timely, responsive, and efficient manner, the likelihood of success increases. Virtual communication protocols that were necessitated during the Coronavirus outbreak may provide VR counselors with advantages going forward in their efforts to keep in touch with individuals and deliver services in a holistic and time-efficient manner. Use of smart phones and group video chat platforms is a cost-effective way to maintain communication regardless of social distancing requirements, provided that VR consumers with SLD have adequate access to mobile technology and the Internet.

Finally, the powerful disincentives to competitive employment that inhere to the SSI and SSDI programs were evident in this study of young adults with SLD. Individuals with SLD who are receiving disability cash benefits at the time of enrollment in VR services are at risk for unsuccessful outcomes by virtue of their benefits status, and it is important to keep in mind that receiving SSI or SSDI benefits is a proxy for a more severe disability (Andrew \& Andrew, 2017). With that in mind, VR counselors must assist transition-age individuals with SLD who are cash beneficiaries in understanding their benefits, the impact of paid employment on those benefits, and formal work incentives that the Social Security Administration has in place to encourage beneficiaries to participate in competitive employment (Kaya et al., 2016). 


\subsection{Limitations}

This study had several limitations that readers should keep in mind when interpreting results. First of all, this study used archival data; therefore, the researchers did not manipulate the variables in this ex post facto study, so causal relationships among study variables cannot be inferred from these findings. Secondly, this study only used data for the fiscal year of 2013 in a cross-sectional rather than longitudinal design. Therefore, we could not examine any patterns in service delivery or VR outcomes over time. The data used in this study were collected throughout the United States. However, individual states have different rules and regulations regarding the provision of VR services. In addition to that, demographic and disability-related characteristics of VR individuals and counselors vary from state to state. Examining those potentially important state-level differences was outside the scope of this study. Finally, the RSA911 data do not provide information regarding the functional levels of individuals and how disability impacts their daily lives, although those variables are known to be important determinants of VR success (Rubin et al., 2016).

\section{Conflict of interest}

None to report.

\section{References}

Andrew, J., \& Andrew, M. J. (2017). Disability handbook. Aspen Professional Services.

Blalock, G. (1996). Community transition teams as the foundation for transition services for youth with learning disabilities. Journal of Learning Disabilities, 29(2), 148-159. https://doi.org/10.1177/002221949602900204

Cameto, R., Marder, C., Wagner, M., \& Cardoso, D. (2003). NLTS2 data brief: Youth employment. Menlo Park, CA: SRI International and National Center on Secondary Education and Transition. Retrieved April 19, 2020, from http://www.ncset.org/publications/viewdesc.asp?id=1310

Cummings, R., Maddux, C. B., \& Casey, J. (2000). Individualized transition planning for students with learning disabilities. Career Development Quarterly, 49(1), 60-72. https://doi.org/10.1002/j.2161-0045.2000.tb00751.x

Daviso, A. W., Denney, S. C., Baer, R. M., \& Flexer, R. (2011). Postschool goals and transition services for students with learning disabilities. American Secondary Education, 39(2), 77-93.

Dunham, M. D., Multon, K. D., \& Koller, J. R. (1999). A comparison of adult learning disability subtypes in the vocational rehabilitation system. Rehabilitation Psychology, 44(3), 248265. https://doi.org/10.1037/0090-5550.44.3.248
Dunham, M. D., Schrader, M. P., \& Dunham, K. S. (2000). Vocational rehabilitation outcomes of adults with co-morbid borderline IQ and specific learning disabilities. Journal of Rehabilitation, 66(4), 31.

Dutta, A., Gervey, R., Chan, F., Chou, C. C., \& Ditchman, N. (2008). Vocational rehabilitation services and employment outcomes for people with disabilities: A United States study. Journal of Occupational Rehabilitation, 18(4), 326-334. https://doi.org/10.1007/s10926-008-9154-z

Fernandes, A. L., \& Gabe, T. (2009, April). Disconnected youth: A look at 16-to-24-year olds who are not working or in school. Congressional Research Service.

Fullarton, S., \& Duquette, C. (2013). Experiences of students with learning disabilities in Ontario universities: A case study. International Journal of Special Education, 31(1), 53-66.

Gonzalez, R., Rosenthal, D. A., \& Kim, J. H. (2011). Predicting vocational rehabilitation outcomes of young adults with specific learning disabilities: Transitioning from school to work. Journal of Vocational Rehabilitation, 34(3), 163-172. https://doi.org/10.3233/JVR-2011-0544

Hendricks, D. (2010). Employment and adults with Autism spectrum disorders: Challenges and strategies for success. Journal of Vocational Rehabilitation, 32(2), 125-134. https://doi.org/10.3233/JVR-2010-0502

Hitchings, W., and Retish, P. (2000). Career Development Needs of Students with Learning Disabilities. In D. A. Luzzo (Ed.), Career Counseling of College Students (pp. 217-231). American Psychological Association.

Individuals with Disabilities Education Improvement Act (IDEA, 2004). Sec. 300.8 (c) (10), Amendments of 2004 (PL 108-446). U.S. Department of Education.

Ji, E., Schaller, J., Pazey, B., \& Glynn, K. (2015). Education and employment outcomes from the RSA data file for transition-age African American, Caucasian, and Hispanic youth with learning disabilities. Journal of Applied Rehabilitation Counseling, 46(3), 15-24. https://doi.org/10.1891/00472220.46.3.15

Kaye, H. S. (2005). Unpublished tabulations of 2005 data from the U.S. Survey of Income and Program Participation. U.S. Census Bureau, Survey of Income and Program Participation (SIPP).

Kaya, C., Chan, F., Rumrill, P., Hartman, E., Wehman, P., Iwanaga, K., Pai, C., \& Avellone, L. (2016). Vocational rehabilitation services and competitive employment for transition-age youth with Autism spectrum disorders. Journal of Vocational Rehabilitation, 45(1), 73-83. http://doi.org/10.3233/JVR-160812

Kleinbaum, D., \& Klien, M. (2010). Logistic regression: A selflearning text (3rd ed.). Springer.

Kohler, P. D., \& Field, S. (2003). Transition-focused education: Foundation for the future. The Journal of Special Education, 37(3), 174-183. https://doi.org/10.1177/ 00224669030370030701

Luecking, R. G., \& Wittenburg, D. (2009). Providing supports to youth with disabilities transitioning to adulthood: Case descriptions from the Youth Transition Demonstration. Journal of Vocational Rehabilitation, 30(3), 241-251. https://doi.org/10.3233/JVR-2009-0464

Mambaleo, G., Kaya, C., Meyer, L., Kamnetz, B., Bezyak, J., \& Chan, F. (2015). Vocational rehabilitation services and outcomes for individuals with arthritis in the United States. Journal of Vocational Rehabilitation, 42(2), 131-139. https://doi.org/10.3233/JVR-150730 
Martin, F. H. (2010). Racial variation in vocational rehabilitation Outcomes: A structural equation modeling approach. Rehabilitation Counseling Bulletin, 54(1), 26-35. http://doi.org/10.1177/0034355209360420

McGee, A. (2011). Skills, standards, and disabilities: How youth with learning disabilities fare in high school and beyond. Economics of Education Review, 31(1), 109-129. https://doi.org/10.1016/j.econedurev.2010.07.008

National Center for Education Statistics (2019). Children and youth with disabilities. Retrieved from https://nces.ed. gov/programs/coe/indicator_cgg.asp

National Center for Education Statistics (2013). Children 3 to 21 years old served under Individuals with Disabilities Education Act (IDEA), Part B, by type of disability: Selected years, 1976-77 through 2011-12. Retrieved from http://nces.ed. gov/programs/digest/d13/tables/dt13_204.30.asp

National Center for Learning Disabilities (2014). The state of learning disabilities. Retrieved from https://www. ncld.org/wp-content/uploads/2014/11/2014-State-of-LD.pdf

National Longitudinal Transition Study 2 (NLTS-2, 2003). The achievements of youth with disabilities during secondary school. SRI International.

Oertle, K., \& Trach, J. (2007). Interagency collaboration: The importance of rehabilitation professionals' involvement in transition. Journal of Rehabilitation, 73(3). 36-44.

Powers, K., Hogansen, J., Greenen, S., Powers, L., \& GilKashiwabara, E. (2008). Gender matters in transition to adulthood: A survey study of adolescents with disabilities and their families. Psychology in the Schools, 45(4), 349-364. https://doi.org/10.1002/pits.20297

Price, L., Gerber, P. J., \& Mulligan, R. (2003). The Americans with Disabilities Act and adults with learning disabilities as employees: The realities of the workplace. Remedial and Special Education, 24(6), 350-358. https://doi.org/ $10.1177 / 07419325030240060601$
Reder, S. (1995). Literacy, education, and learning disabilities Northwest Regional Educational Laboratory.

Rehabilitation Services Administration (2005). RSA-PD-06-01 Reporting manual for the case service report (RSA 911). Rehabilitation Services Administration. https://www2 ed.gov/policy/speced/guid/rsa/pd-06-01.pdf

Rubin, S., Roessler, R., \& Rumrill, P. (2016). Foundations of the vocational rehabilitation process (7th ed.). Pro-Ed.

Sabbatino, E. D., \& Macrine, S. L. (2007). Start on success: A model transition program for high school students with disabilities. Preventing School Failure, 52(1), 33-39. https://doi.org/10.3200/PSFL.52.1.33-40

Smart, J. (2020). Disability and diversity across the lifespan. ProEd.

Strauser, D. (2014). Introduction to the centrality of work. In D. R Strauser (Ed.), Career development, employment and disability in rehabilitation: From theory to practice. Springer Publishing Company.

Swanson, L. (2017). Searching for the best model of instructing students with learning disabilities. Focus on Exceptional Children, 34(2), 1-15. https://doi.org/10.17161/foec.v34i2.6785

United States Department of Education. (2007). Transition of students with disabilities to postsecondary education: A guide for high school educators

United States Department of Labor (2015). Youth employment rate http://www.dol.gov/odep/categories/youth/youthemployment. htm

Winn, S., \& Hay, I. (2009). Transition from school for youths with a disability: Issues and challenges. Disability \& Society, 24(1), 103-115. https://doi.org/10.1080/09687590802535725

Wehman, P., Sima, A. P., Ketchum, J., West, M. D., Chan, F., \& Luecking, R. (2015). Predictors of successful transition from school to employment for youth with disabilities. Journal of Occupational Rehabilitation, 25(2), 323-334 https://doi.org/10.1007/s10926-014-9541-6 